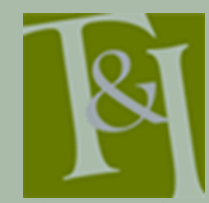

The International Journal for Translation \& Interpreting Research trans-int.org

\section{Think aloud protocols: Viable for teaching, learning, and professional development in interpreting}

\author{
Amanda Smith \\ Western Oregon University, USA. \\ smithar@wou.edu
}

DOI: ti.106201.2014.a07

\begin{abstract}
Interpretations are as unique as the professionals who produce them. That being the case, how do we find out what factors contribute to choices made in an interpretation, particularly when a majority of the work tasks involved in the interpreting process occur, unobservable, in the brain of the practitioner. Think Aloud Protocols (TAP) provide a means for gaining access to the inner workings of interpreting practitioners. TAPs have been used in researching translation between two written languages but applying the research method to signed language interpreters has required a bit of adaptation as performing a TAP during simultaneous, or even consecutive, work is cumbersome to near impossible. In studying the inner workings of signed language interpreters, TAPs can be used effectively to access the thinking during preparation for the task of simultaneous interpreting and then again in accessing the thoughts in reviewing the simultaneous work just produced. The use of TAPs are effective in informing many aspects of interpreting work that have long been hidden from inspection, including, but not limited to: decision-making process, facts that influence translation choices in the moment, and monitoring \& correction strategies. TAPs, with modifications, are just as viable for accessing the inner workings of interpreters working in real time, simultaneously or consecutively as for use with translator's work.
\end{abstract}

Keywords: think aloud protocol; signed language interpretation; reflective practice; assessment; teaching.

\section{Introduction}

In the work of interpreters, much is left unseen. This is not dissimilar to other professions where much of the work happens internally, for example, computer engineers, nurses, and teachers. We often see the results of the mental work but without a precise level of expertise, we are left only to infer what happens internally.

The internal nature of the work interpreters do serves a great purpose in the actual execution of the work. If our work primarily took place externally it would be quite distracting for the other participants. Thus, the fact that it is internal is a significant asset.

The use of think-aloud protocols (TAPs) to collect data at a number of points in the process provides a plethora of data for an interpreter or professor to review in developing a plan of action for improving one's work product and thus increasing the effectiveness of communication experienced by the consumers. The forced articulation of the TAP process allows one to uncover and discover aspects of their work practice and process that they may have overlooked for some time. 
Interpreting is primarily a mental game. There is external evidence of the internal processes that take place. Similar to how you can see evidence of the wind blowing because the tree leaves are moving but you cannot actually see the wind. Interpreters use language and facilitate communication between two parties using different languages. This is the evidence that work is being done; however, an interpreter's actual work cannot be directly observed (see Gile, 1988, 1999; Moser-Mercer, 1997, 2000; Pockhacker, 2004; Roy, 1999). That work is hidden away in the depths of their mental process. As a researcher and trainer of interpreters, I want to know what happens in those deep inner processes. Without that knowledge how do I know what to teach the next generation? How do I assist them in developing those inner workings of their own? How do I understand my own work as a practitioner? There is gold in that unobservable world and I want to unearth that treasure.

When focused solely on the final product, it is much like focusing just on the final destination of a journey with no regard or attention to the journey itself. There are a myriad of ways to arrive at the final product, or chosen destination. Knowing the route taken, pitfalls encountered, and choices made contextualizes the final product in a more rich and full way.

Think Aloud Protocols (TAPs) are used in a number fields (e.g., teaching, nursing, computer programming) to reveal the facets of a process that a subject is undertaking rather than relying only on the single data point of the final product (see Cohen \& Hosenfeld, 1981; Hayes \& Flower, 1980). For example, a subject may be asked to conduct a computer processing task and "think aloud" while doing so. They are asked to utter everything going on in their mind at the time. They may be prompted with questions such as, what they are looking at, thinking about, doing or feeling while performing the assigned task. This process, upon first glance, may seem impossible to apply to interpreters working simultaneously between two languages, but it can be a quite helpful tool, with slight modifications.

When working between two languages simultaneously, or even consecutively, there may no cognitive space remaining to add a third level of language use during the process. However, the TAP protocol can still be useful if interpreters are asked to talk about their preparation for the task, their response to static stimuli (scenario) or their reflections upon work that was just produced (thus fresh in their minds). This process also allows one to establish self-reflective practices to hone and refine one's work as they develop professionally.

In the field of signed language interpretation, there is a long history of seasoned interpreters training up the next generation with the mantra, "it depends." This is the most common answer provided an aspiring interpreter. The seasoned interpreter knows what is meant and their peers do as well due to a shared sense of experience. However, to the aspiring interpreter it is the same as responding "because" to a child's question about why the leaves are moving on a tree. They need to understand the wind, they need to understand how it works, what causes it, what contributes to it, and how it behaves differently in different circumstances so that they know when to respond by enjoying the breeze and when to seek cover from the tornado. "Because" is not going to give them sufficient insights, nor will "it depends" give aspiring interpreters a sense of how they could respond in their work.

That being said, the internal nature of our work creates challenges in fully appreciating the complexity of the tasks involved in transferring meaning between two languages. Additionally, challenges in identifying areas of strength and weakness in our work, identifying the root of potential errors that occur with some regularity in our work, and perhaps most of all it creates a barrier between practitioners and those who seek to be practitioners in the future. How can we educate future generations without the ability to 
articulate what it is we know about our own work and what makes it effective? As interpreters, the internal, mental landscape is rich with data. We need only determine a way to extract that data and take the time necessary to do so.

Think Aloud Protocols, in which the practitioner articulates the thoughts running through their head with no editing is an effective tool for accessing this rich data (Ericsson \& Simon, 1984, 1993; Gerloff, 1986). Consequently, once this data is accessed, it can be analyzed for professional development, researched for a better understanding of the work, and even transmitted to future generations. Teaching others how to think like interpreters earlier in their career is of great benefit when compared to the experience of those who went through the "school of hard knocks."

TAPs lead to discovery about the inner workings of interpreters working consecutively and simultaneously with signed and spoken languages. TAPs are a versatile tool that can be utilized in preparation for work, in reflection of work, and sometimes during the work itself (if consecutive). This tool can be used by pre-professional interpreters as they are developing their skills, professors in teaching the next generation, and by practicing interpreters to heighten their awareness of their process as a means of professional development.

In this paper, I outline a number of tools that have been found to be effective in my practice as an interpreter, mentor, and professor of interpreting. A brief review of the literature regarding think aloud protocols, interpreting work analysis, and teaching begins a discussion of practical applications for the use of TAPs. This is followed by a discussion of how to analyze the data gathered from the TAPs and how to use that data in enhancing one's practice.

\section{Conceptual Framework}

The work of interpreting is not a simple linear conversion process, it is multi-faceted and highly "recursive and iterative process" as described by Göpferich \& Jääskeläinen (2009). Thus there have been multiple successful attempts at conceptualizing the work using various models and frameworks. Models of process and interaction, frames including those from a sociolinguistics or multicultural bent (see Pochhacker, ch. 5, 2004).

Regardless of the manner in which the work is conceptualized, the goal is to contribute to effective communication between parties not sharing the same language. This value is evident throughout the Registry of Interpreters for the Deaf's Code of Professional Conduct tenets. Effective communication, however, is an elusive goal in that there are so many factors that contribute to effectiveness.

Addtionaly effectiveness is not a matter of being or not: there are levels of effectiveness. There is effectiveness in the communication event versus effectiveness of the interpretation processsto name two. The research available on effectivenss of interpretations is limited and geared primarily to educational settings (see Livingston et al., 1995; Marsharck et al., 2005; and Napier, 2004a; for discussion of these effectivenes studies). Primarily the focus was on the performance of the Deaf student upon receiving content via an interpretation (effectiveness being determined by test scores).

This further supports the notion that accessing the actual interpretation process and determining its efficacy is near impossible. One can only be privy to the results of the interpretations. Various data sets allow for multiple levels of analysis and development of potential interventions. This paper in no way intends to place these data sets and analysis techniques in a 
hierarchical fashion, but rather to add a tool to the list of viable options when approaching the goal of assessing effectiveness in interpretation.

\subsection{Product and Process Lenses}

In analyzing the work of interpretation (meaning transfer and professionalism as a whole), there are many ways to collect data. In this paper, the emphasis will be on data collection for improvement of the work rather than on data collection for academic research purposes.

The two main lenses through which interpreting work is viewed in the literature are product and process (see Pochhaker, ch. $6 \&$ 7, 2004). Product focuses on the results of the mental interpretation and decision-making process, the tangible output. The process lense, in contrast, attempts to focus on and analyze the inner workings of the mental process that takes place in the mind of the interpreter. A much more elusive target that is typically pieced together by using methods from cognitive science (Pochhacker, 2004, p. 113).

This can be likened to teaching and learning math concepts. One can focus on whether or not the right (or at least acceptable) answer was achieved, or one can focus on the accuracy of the process one went through in deriving the answer (regardless of its accuracy). These two tasks, though related, net very different data and different results. Knowing why a decision was made or how an answer was derived assists in pinpointing the areas needing attention to achieve a more acceptable outcome in the future.

Research into the process of translation is relatively new, with the initial studies and methodologies being developed in the late 1980s (see Göpferich \& Jääskeläinen, 2009). Prior to that and even still, much of the research on interpreting has to do with the product focusing on miscues, errors, acccuracy, fidelity and other products of interpreting work (see Cokely, 1986; Napier 2004; Taylor 1993, 2002).

As stated above, there are a myriad of ways to conceptualize of the work of interpreting, in Figure 1, the graphic depicts interpreting in a rather simplistic way to show the parties involved and a bit of the co-construction involved in the process (Wilcox \& Shaffer, 2005). The goal is to discuss data collection and analysis methods, not the interpreting process necessarily.

Figure 1. Conceptual Framework

Goal: Effective Interpretation

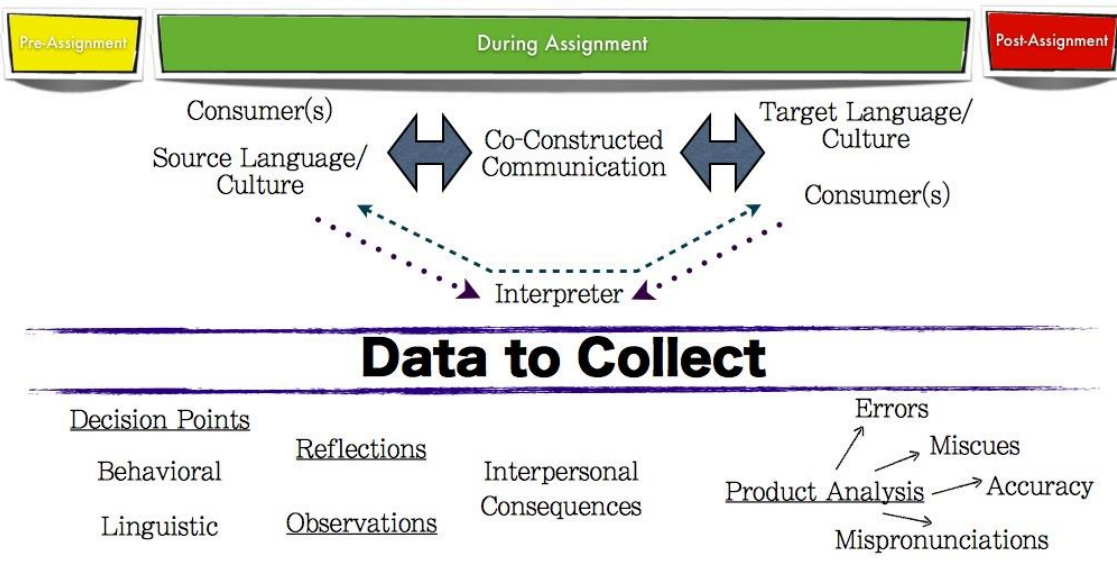

\section{Proposed Collection Method}

Teaching \& Learning

This figure depicts the framework that led to multiple uses of Think Aloud Protocols in teaching, learning, and reflective practice for the author. 


\subsection{Think Aloud Protocols}

There is research available on the topic of TAPs used in language translation (see Bernardini, 1999; Göpferich \& Jääskeläinen, 2009; Kam-mei, 1994; Li, 2004; Whittington et al., 2000). There is not yet a strong literature base for TAPs being employed among signed language interpreters.

The main emphasis of the TAP is to collect data on the individual interpreter's mental process, not only the interpretation product. The use of Think Aloud Protocols (TAPs) in researching spoken language interpreting has proven to provide new insight in to the mental processes that translators experience while working to translate a text. Silvia Bernardini talks about the usefulness of TAPs:
Insofar as it is not possible to directly observe the human mind at work, a number of attempts have been made at indirectly accessing the translator's mind. One such attempt, which has been steadily gaining ground in translation research, has been to ask the translators themselves to reveal their mental processes in real time while carrying out a translation task. (Bernardini, p. 1).

The use of TAPs to unravel the mind of a translator is just beginning to be applied to the work of signed language interpreters in education programs for pre-professional and professional interpreters (Stone, 2012). Though there is limited mention in the current literature, I am aware of the inclusion of TAPs from my personal experience in my graduate program, my own teaching, and conversations with colleagues about their teaching over the years (E. Maroney, personal communication; S. Storme, personal communication).

As illustrated to this point, TAPs do have a number of benefits. There are, however, limitations to the use of TAPs as well. As Branch (2000) points out in her abstract, "concurrent verbal protocols have been seen to cause problems when the task involves a high cognitive load" such as would be found in simultaneous or consecutive interpreting.

Additionally, having another linguistic factor added to the already heavy linguistic load of interpreting can skew the task being done as well as the utterances in the TAP (Li, 2004). In signed language interpretation, there is the additional layer of change in modality that takes place during interpretation between a spoken language and a signed language.

At this writing, I am not aware of research on the implications of modality switch during interpretation but one can imagine it would at least be a factor for consideration. There is, however, research on the use of codeblending among bilingual-bimodal individuals that might suggest it is less of an issue than I think (Emmorey, 2005).

Another factor I have found in my use of TAPs in the classroom and in my personal work is that it is a learned skill to be able to verbalize one's thoughts. People are wired in different ways, some process internally and others externally. TAPs come more naturally for external processors. TAPs however can be learned over time.

Thus, the data gleaned from initial TAPs may be more superficial when compared to data from later TAPs when one has developed a level of mastery in verbalizing thoughts, regardless of their hard wiring. In Figure 2 are sample instructions for conducting a TAP. 
Figure 2. Sample instructions for TAP

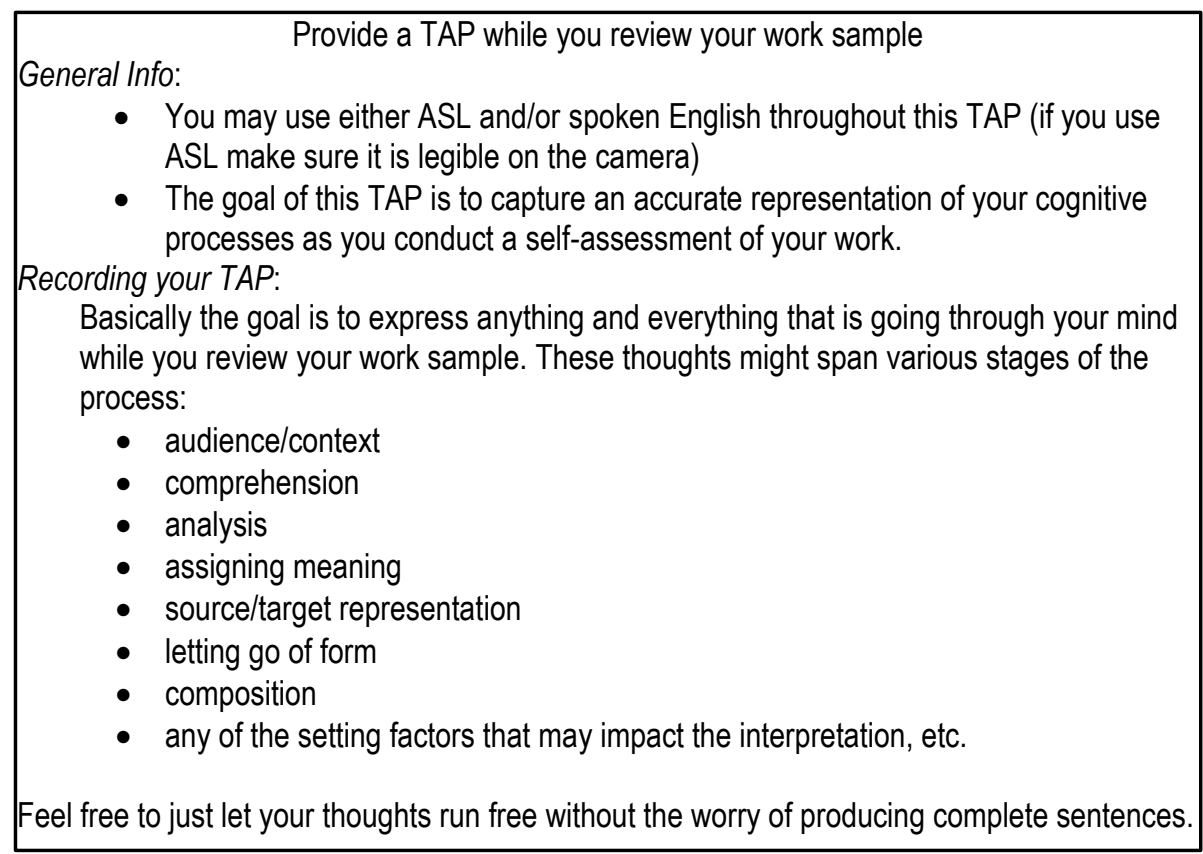

\subsection{Teaching \& Learning}

Though predominantly the literatrue discusses TAPs as a means of research and discovery, there are applications of this tool for teaching, learning, and developing a "reflective practice" (Schön, 1983) as a practitioner. Teaching and learning go hand in hand and below are ideas for the implementation of TAPs in the classroom. After exploring the use of TAPs for transmission and development of skills and knowledge, the use of TAPs for on-going reflective practice will be discussed.

Learning is not merely a passive activity, as Kiraly points out the social constructivist approach to interpreter education requires more than "the memorization of discrete pieces of knowledge" (2000, p. 23). Through the use of modeling, inquiry, and authentic tasks in the interpreting classroom, students can gain a sense of their capabilities and limitations. This situated learning the mimics the real world places real-world pressures on the students and elicits real-world responses. Delving into those practices and responses, allows students insight into their process and creates opportunity for them to exert more purposeful control over their process thus resulting, hopefully, in a higher quality product.

Teaching. Pre-professional interpreters do not begin already knowing how to think about approaching interpreting. For example, what are the factors or demands (Dean \& Pollard, 2001, p. 1) that need to be considered? What is relevant in the situation? What are the options (linguistic, behavioral, or internal) available? Which ones could/should be considered?

These are valid questions given the internal nature of the work of interpreting. There is not a mechanism for observing the answers without intentional insight being shared by the observed practitioner.

Thus, a potential tool is to conduct a TAP as the professor, an experienced interpreter, using the source material assigned to students, regardless of whether it is meaning transfer or ethical in nature. This can also be an effective activity when inviting in community partners and experts from the field.

Through this, aspiring interpreters gain insight into the inner workings made explicit by the practitioner being observed. Having sample TAPs by professionals can assist students in developing professional-like thinking 
earlier in their journey toward professionalism - providing language, insight, and parameters for thinking through dilemmas they face in their studies and eventually in their professional work.

Table 1. Ideas for implementing TAPs in the classroom as a form of modelling

\begin{tabular}{|c|c|}
\hline Who & In Response to \\
\hline Professor & $\begin{array}{c}\text { •Assigned Source Material } \\
\text { "What if" scenarios from students } \\
\text { •Assigned Scenario }\end{array}$ \\
\hline Professional Interpreter & \\
\hline Community Member & \\
\hline
\end{tabular}

Learning. TAPs in the learning process allow students to plainly see what they know and what they still question.

In my experience, often students believe that they will respond in a particular (theoretically appropriate) way when faced with a set of hypothetical demands. However, when faced with those demands and required to respond, not hypothetically, they find themselves with emotions, thoughts, or impulses that do not correspond with the perception they hold of themselves.

Uncovering those areas of one's self prior to professional practice is critical in developing skills to think through, assess, and determine an appropriate course of action. Without the overt articulation of one's beliefs, responses, and impulses it is difficult, at best, to address any of those areas (see Dean \& Pollard (2006) for a more thorough discussion of the implications of "thought world" and personal frames on the work of interpreters). This applies to behavioral and attitudinal practices alike, it also does not exclude approaches and thoughts to meaning transfer work.

People have long-held beliefs about communication, meanings of words and phrases, ways of communication and other areas of interpersonal communication that play heavily into our work as interpreters. Uncovering the lenses through which we view the world allows us to recognize our internal bias and to acknowledge the impact it has on our work.

TAPs are an effective tool for uncovering much of this internal, unexamined landscape. Table 2, below, outlines potential ways of implementing this tool in the learning process.

Table 2. Ideas for implementing TAPs in the classroom as a form of assessment \& discovery

\begin{tabular}{|c|c|}
\hline Who & In Response to \\
\hline Student & $\begin{array}{c}\text { •Assigned Source Material } \\
\bullet \text { Assigned Scenario } \\
\text { •Work Sample } \\
\text { Peer }\end{array}$ \\
\hline Mentor & Sample of Professional Work \\
\hline
\end{tabular}


As mentioned above and depicted in Figure 3 below, the process of teaching, learning and reflective practice is interdependent.

Figure 3. Teaching, Learning and Reflective Practice.

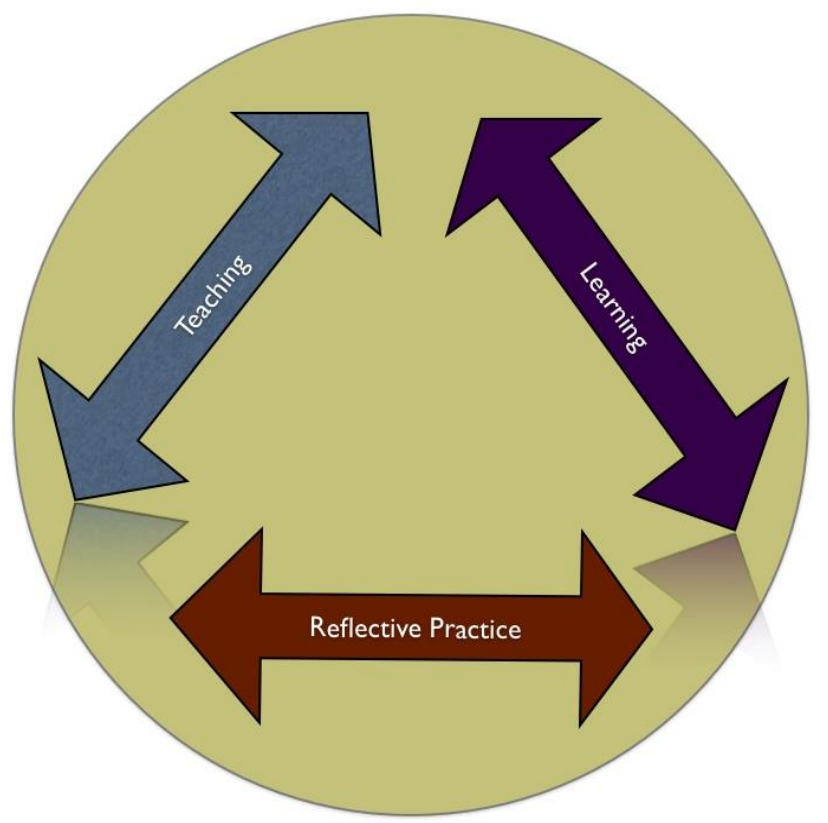

This figure shows the cyclical nature of the teaching, learning, and reflective practice process.

As one transitions away from being a pre-professional in a formalized classroom where a professor structures the learning process, there is also a transition of ownership of the work. At some point in that transition, the practitioner must take ownership of their own professional development process.

\subsection{Reflective Practice}

As we practice, we develop habits of doing our work. Through this process many aspects of our work become automated (see Moser-Mercer, et al., 2000). The need to automatize aspects of our work is a means of selfpreservation, we cannot possibly attend fully and consciously to all aspects of our work simultaneously. However, over time, some of the automated aspects of our work become sloppy and deserve re-examination. Using TAPs as we develop and mature as practitioners allows once learned and mastered skills to be revisited. Ensuring that those skills continue to function at peak performance.

Table 3. Ideas for implementing TAPs as reflective practice. ${ }^{1}$

\begin{tabular}{|c|c|}
\hline Who & In Response to \\
\hline Practitioner & $\begin{array}{c}\text { •Professional Work Sample } \\
\text { Reflection of work just produced } \\
\text { •Dialogue with a teammate }\end{array}$ \\
\hline
\end{tabular}

\footnotetext{
${ }^{1}$ See Göpferich \& Jääskeläinen (2009) for more on use of dialogue in the TAP process.
} 


\section{Methods}

The basic construct of a TAP is rather simple: verbally report thoughts that are occurring in real time. Below are specific ways in which this simple technique can be applied to gain insight into one's work.

\subsection{Practical Application}

In the following section, I will share practical applications that I have employed in my classroom and in my own development as an interpreter.

There are many more applications and my hope is that this opens discussion about the potential uses and limitations of this technique among practitioners. An arbitrary division in aspects of the interpreting process is evident in much of the literature: that of meaning transfer, and professional (or ethical) decision-making. There will be a section focused on various uses in teaching, learning and reflecting on meaning transfer and then on decision making (might also be referred to as ethical decision-making).

Figure 4 outlines these areas and shows sample applications which are discussed in further detail below.

Figure 4. Potential areas in which to implement TAPs.

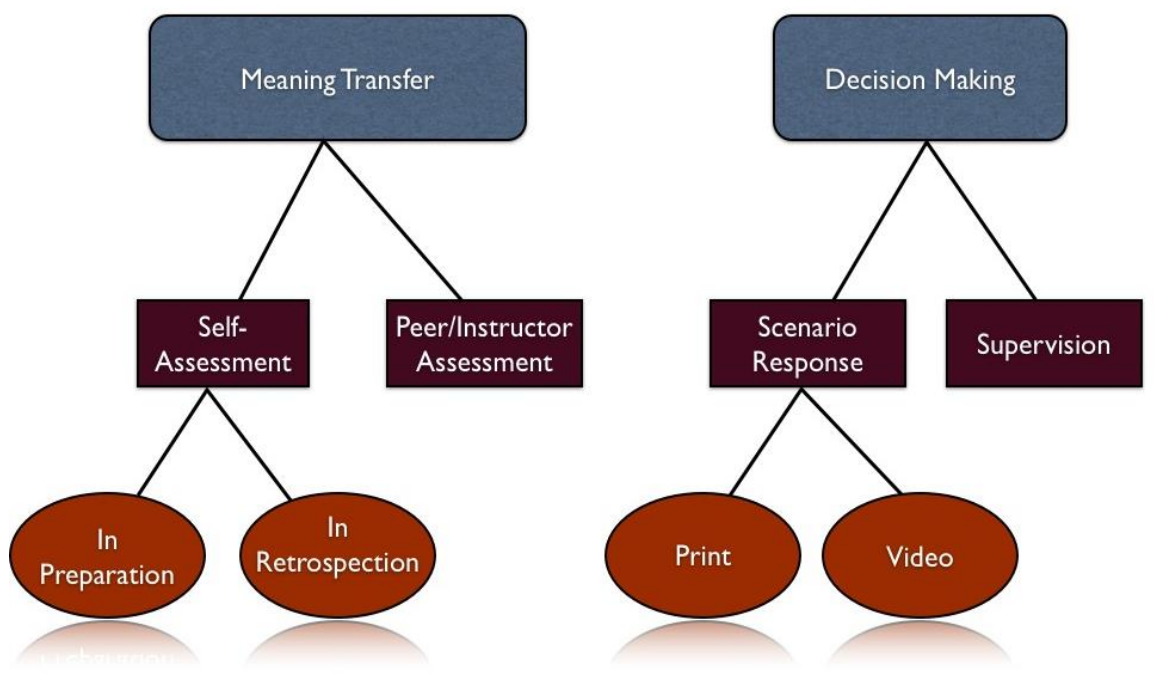

\subsection{Meaning Transfer}

In Preparation. Provide a scenario for an upcoming assignment. Once reviewed, the pre-professional is asked to mentally prepare verbalizing each of their thoughts \& considerations about the job without need to edit or even form coherent thoughts, the most important thing is for them to continue verbalizing, like a continuous stream of consciousness (see Figure 2 above for sample instructions).

In Retrospect (A). Upon completing the preparation TAP, participants are asked to perform a simultaneous or consecutive piece of work (upon which the scenario in 3.1.1.1. was based). Once the interpretation is complete, participants are asked to reflect on their work (without viewing). What thoughts and impressions do they have about the work, what do they recall? Again, structure and coherence are secondary to verbalization of each thought the participant has about the work. 
In Retrospect (B). Once the participant's reflections are complete, they can then review video of their work, just produced, and are asked to verbalize their thoughts during the playback. Some sample prompts (to be included in instructions ahead of time not asked during TAP) include:

- What was going on in your head?

- Did you remember it correctly; do you have a different impression now than when they were merely relying on your memory of the experience?

- What is your impression of the work as you see it?

- What do you notice about your work?

During this process the participant can pause the playback if their utterances around a particular clip of the video will require more time to express.

In Assessment. Retrospective (B), above, can be a self-assessment. A peer and/or professor assisting in data collection for assessment would record themselves doing a TAP while reviewing another's work. The video includes commentary, thoughts, questions, and suggestions. This can be done using a built-in webcam on a laptop or even using screencapturing software programs to capture the work and the TAP simultaneously. This can be as low or high tech as the person conducting the TAP.

TAPs can be an effective tool for professors in reviewing other's work. As a reviewer, you can provide a TAP based on viewing a work sample. This provides opportunity for questions to be posed, ideas to be shared, patterns to be identified and suggestions to be given that correspond to the actual interpretation produced. For example, I use a program called Camtasia that allows for screen capture and video recording of my TAP. This means I can provide commentary, prompts, questions, and suggestions in either spoken English or ASL and the student can view it in concurrently with their work sample.

Benefits to Teaching and Mentoring. The process outlined above can be an enlightening experience for the practitioner as well as the researcher and professor. It allows the participant to view their own work and make sense of their own mental process. This is data that outsiders would not have access to normally. For a professor it allows the insight of what was happening mentally during the process allowing more precise instruction to follow.

Professionalism. TAPs can also be beneficial in the development of professional, ethical decision-making processes. Providing scenarios, in segments, to working interpreters and asking them to verbalize their mental process in response to such real-life scenarios can again provide examples to pre-professional interpreters in terms of how interpreter's think and approach situations requiring professional discretion.

I was first introduced to this process during my Master's in Interpreter Pedagogy program at Northeastern University, it was called an "Ethical Unfolding Scenario." The idea is that respondents are asked to TAP their reactions to a scenario that is revealed in stages, not all at once. There is more added to the scenario each time and requires continuing responses and perhaps even deeper levels of processing.

Additionally, as an assessment, professors can provide scenarios to preprofessional students and ask them to respond in a TAP format, eliciting their real thoughts and reactions to a given situation. The student has an opportunity to see how they would react in real time to a situation, not as hypothetically as a "what if" discussion. For professors, they are able to identify gaps in knowledge or skill that need to be incorporated into future lessons. 
In Retrospect (Supervision ${ }^{2}$ ). Though not technically a TAP, supervision sessions with colleagues and mentors do require articulation of one's perception of the context in which they worked, the thought process they underwent when making decisions, and their assessment of their choices effectiveness. This verbal articulation - the slowing down of the process of decision-making - garners many of the same benefits of a TAP, with the added benefit of having peers and colleagues share in the analysis.

This benefits not only the person sharing their context but the members participating as well.

\section{Findings}

Conducting a TAP does not magically provide insight, the treasure lies in the analysis. The overarching goal is to seek patterns of thought, choice, and behavior. Once identified then discussion can ensue as to the implications of those patterns and potential interventions. This paper will not delve into potential interventions, that is for another writing, but will provide examples of what patterns or revelations may look like.

Table 4 below outlines areas I have identified in reviewing my own work or other's work. The example utterances are merely intended to be illustrative of what one might encounter in reviewing a TAP. This is a compilation of utterances from myself or my students over the years, not direct quotes. The last column identifies what those utterances may point to as an area for attention in one's work.

Table 4. Data revealed via analysis of TAPs.

\begin{tabular}{|c|c|c|}
\hline Patterns Revealed & Example Evidence & $\begin{array}{l}\text { What it might point to if } \\
\text { consistent throughout }\end{array}$ \\
\hline Depth of Processing & $\begin{array}{l}\text { "I'm not sure [of] the sign for } \\
\text { X." } \\
\text { "I'm thinking the frame of } \\
\text { reference of the consumer } \\
\text { base would be X, meaning I } \\
\text { might need to frame the } \\
\text { content in this way." }\end{array}$ & $\begin{array}{l}\text { Lexical level processing } \\
\text { Contextual level processing }\end{array}$ \\
\hline Vocabulary Range & $\begin{array}{l}\text { "I noticed I use 'very' a lot" } \\
\text { "I referred to that same } \\
\text { concept accurately in three } \\
\text { different ways" }\end{array}$ & $\begin{array}{l}\text { limited vocabulary } \\
\text { extensive vocabulary but lack of } \\
\text { consistency }\end{array}$ \\
\hline $\begin{array}{l}\text { Co-construction of } \\
\text { meaning }\end{array}$ & $\begin{array}{l}\text { "That signs means X" } \\
\text { "I wonder if the consumer } \\
\text { would get what the speaker } \\
\text { was talking about in the way } \\
\text { they framed it" }\end{array}$ & $\begin{array}{l}\text { belief that languages are } \\
\text { isomorphic } \\
\text { recognition that communication is } \\
\text { multifaceted }\end{array}$ \\
\hline
\end{tabular}

${ }^{2}$ As defined by Dean \& Pollard $(2004,2009)$ 


\begin{tabular}{|c|c|c|}
\hline Patterns Revealed & Example Evidence & $\begin{array}{l}\text { What it might point to if } \\
\text { consistent throughout }\end{array}$ \\
\hline $\begin{array}{l}\text { Contextual } \\
\text { Considerations }\end{array}$ & $\begin{array}{l}\text { "I don't know what that word } \\
\text { means" } \\
\text { "I missed the exact word } \\
\text { fingerspelled but the context } \\
\text { meant X" }\end{array}$ & $\begin{array}{c}\text { belief that languages are } \\
\text { isomorphic and not context based } \\
\text { Recognition that conveying } \\
\text { meaning can happen at various } \\
\text { levels }\end{array}$ \\
\hline $\begin{array}{l}\text { Extralinguistic } \\
\text { Knowledge }\end{array}$ & $\begin{array}{l}\text { "I'm familiar with } X \text { and how } \\
\text { that functions as an } \\
\text { organization in the community, } \\
\text { l've experienced } Y \text { and know } \\
\text { what it feels like" }\end{array}$ & world knowledge \& awareness \\
\hline $\begin{array}{l}\text { Intrapersonal } \\
\text { Demands }\end{array}$ & $\begin{array}{l}\text { "I was so nervous with you } \\
\text { watching me work" } \\
\text { "I wasn't sure if that made } \\
\text { sense so I said it another } \\
\text { way" } \\
\text { "I realized that I have an } \\
\text { interest in the outcome of } \\
\text { this interaction" }\end{array}$ & $\begin{array}{l}\text { self-talk patterns } \\
\text { factors impacting choices } \\
\text { adequacy of internal monitor } \\
\text { while working }\end{array}$ \\
\hline Models Employed & $\begin{array}{l}\text { "As I was receiving the } \\
\text { message and considering the } \\
\text { contextual analysis, I missed } \\
\text { the next utterance" }\end{array}$ & $\begin{array}{l}\text { conceptualization using the } \\
\text { Colonomos (1992) model }\end{array}$ \\
\hline Ethical Reasoning & $\begin{array}{l}\text { "I prioritized communication } \\
\text { over accuracy" } \\
\text { "I don't know why it just } \\
\text { seemed like that was what I } \\
\text { was supposed to do" }\end{array}$ & $\begin{array}{c}\text { level of ethical awareness } \\
\text { frame through which one views } \\
\text { decision-making }\end{array}$ \\
\hline
\end{tabular}

This table shows types of findings from TAPs and examples of what the evidence may look like.

The beauty of a TAP is in allowing the unobservable to be accessed. TAPs can reveal the level of processing an interpreter is employing, gaps in their vocabulary, abilities in co-construction of meaning, the level of consideration for contextual factors, the amount of and effective utilization of extralinguistic knowledge (Gile, 1992) while attempting to effectively transfer meaning between two languages and consumers.

\subsection{Know Thyself}

In my use of TAPs for professional development, for training future interpreters and in research, I have found time and again that the data revealed via a TAP provides insight that was not be gleaned another way. In my own work TAPs have functioned to uncover underlying patterns and thoughts much in the same way that a "freewrite" (continuous writing for a period of time without stopping or editing) does (Elbow, 1991). I have uncovered hidden biases that show up in my work, barriers to processing, 
and patterns of miscues that have led to improved work product once addressed.

As a professor, I have employed TAPs to help students become more self-aware both in the meaning transfer process and in professional thinking $\&$ decision-making. This has led to discoveries on their part ranging from, "I didn't know I could get so mad at someone," to "I notice every time there is a fingerspelled word, I miss the next bit of information" (students, personal communication, 2009-2012). In addition to heightening self-awareness, it has been an excellent tool for peer assessment. Asking a student to provide a TAP while observing another's work elicits questions, comments, and suggestions in real time for the working student. This requires trust to be established, the students must earn the right to speak into one another's work. Once they do, it is a great tool for both the working student and the peer assessor to gain insights about the work.

\section{Conclusions}

Though TAPs are not a panacea for diagnosing all the challenges faced by interpreters, there are a number of benefits to its uses in teaching, learning and development of reflective practice in interpreting. Adding the analysis of process oriented data to product oriented data is critical to understanding the full picture of one's work.

As more professors and practitioners employ this strategy in their work, more will be uncovered concerning the complex task of interpreting. More information and deeper understanding of the work will hopefully lead to enhanced effectiveness in transferring knowledge and skill to future generations of interpreters.

TAPS are an effective means for discovering the inner workings of interpreters working consecutively and simultaneously with signed language and spoken language. TAPs bring new knowledge and insight about the work of interpreting. It allows researchers, professors, and practitioners to access data that is normally unobservable during the process of interpreting.

In the work of interpreters, much is left unseen. This is not dissimilar to other professions where much of the work happens internally, for example, computer engineers, nurses, and teachers. We often see the results of the mental work but without a precise level of expertise, we are left only to infer what happens internally.

The internal nature of the work interpreters do serves a great purpose in the actual execution of the work. If our work primarily took place externally it would be quite distracting for the other participants. Thus, the fact that it is internal is a significant asset.

The use of TAPs to collect data at a number of points in the process provides a plethora of data for an interpreter or professor to review in developing a plan of action for improving one's work product and thus increasing the effectiveness of communication experienced by the consumers.

The forced articulation of the TAP process allows one to uncover and discover aspects of their work practice and process that they may have overlooked for some time. 


\section{References}

Bernardini, S. (1999). Using think-aloud protocols to investigate the translation process: methodological aspects. In J. N. Williams (Ed.), REAL Working Papers in English and applied linguistics, 6 (pp. 179 199). Cambridge: University of Cambridge.

Branch, J. L. (2000). The trouble with think alouds: Generating data using concurrent verbal protocols. CAIS 2000: Dimensions of a global information science.

Christoffels, I. K., de Groot, A., \& Kroll, J. F. (2006). Memory and language skills in simultaneous interpreters: The role of expertise and language proficiency. Journal of Memory and Language, 54(3), 324-345.

Cohen, A. D., \& Hosenfeld, C. (1981). Some Uses of Mentalistic Data in Second Language Research. Language Learning, 31(2), 285-313.

Cokely, D. (1986). The Effects of Lag Time on Interpreter Errors. Sign Language Studies, 53, 341-76.

Cokely, D. R. (1985). Towards a sociolinguistic model of the interpreting process: focus on ASL and English. (Doctoral dissertation, Georgetown University).

Colonomos, B. (1992). Processes in interpreting and transliterating: Making them work for you. Westminster CO: Front Range Community College.

Colonomos, B. M. (1989). Depth of processing. Riverdale, MD: The Bicultural Center.

Dean, R. K., \& Pollard, R. Q (2009). "I don't think we're supposed to be talking about this:" Case conferencing and supervision for interpreters. VIEWS, 26(Fall), 28-30.

Dean, R. K., \& Pollard, R. Q. (2001). The application of demand-control theory to sign language interpreting: Implications for stress and interpreter training. Journal of Deaf Studies and Deaf Education 6 (1), $1-14$.

Dean, R. K., \& Pollard, R. Q. (2006, October). From best practice to best practice process: Shifting ethical thinking and teaching. In E. Maroney (Ed.), A New Chapter in Interpreter Education: Accreditation, Research and Technology. Proceedings of the $16^{\text {th }}$ National Convention of the Conference of Interpreter Trainers (pp. 119-32). Monmouth, OR: CIT.

Dean, R. K., Davis, J., Barnett, H., Graham, L. E., Hammond, L., \& Hinchey, K. (2003). Training medically qualified interpreters: New approaches, new applications, promising results. RID Views, 20(1), 1012.

Emmorey, K., Borinstein, H. B., \& Thompson, R. (2005). Bimodal bilingualism: code-blending between spoken English and American Sign Language. Proceedings of the 4th International Symposium on Bilingualism, 663-673.

Ericsson, K. A. (2005). Superior decision making as an integral quality of expert performance: Insights into the mediating mechanisms and their acquisition through deliberate practice. In H. Montgomery, R. Lipshitz, \& B. Brehmer (Eds.), How professionals make decisions (pp. 135-167). New Jersey: Lawrence Erlbaum Associates.

Gerloff, P. (1986). Second language learners' reports on the interpretive process: Talk-aloud protocols of translation. Interlingual and intercultural communication, 243-262. Tübingen: Gunter Narr.

Gerloff, P. A. (1988). From French to English: a look at the translation process in students, bilinguals and professional translators. UMI Dissertation Services.

Gile, D. (1999). Testing the Effort Models' tightrope hypothesis in simultaneous interpreting-A contribution. Hermes, 23, 153-172. 
Gile, D. (2009). Basic Concepts and Models for Interpreter and Translator Training (revised edition) (Vol. 8). John Benjamins Publishing.

Göpferich, S., \& Jääskeläinen, R. (2009). Process research into the development of translation competence: Where are we, and where do we need to go? Across Languages and Cultures, 10(2), 169-191. doi: 10.1556/Acr.10.2009.2.1

Harvey, M. A. (2003). Shielding Yourself From the Perils of Empathy: The Case of Sign Language Interpreters. Journal of Deaf Studies and Deaf Education, 8(2), 207-213.

Hayes, J. R., \& Flower, L. S. (1980). Identifying the organization of writing processes. In L. Gregg \& E. Steinberg (Eds.), Cognitive processes in Writing (pp. 3-30).[1980]

Kam-mei, J. L. (1994). The thinking-aloud protocol in the investigation of the translation process. Meeting Points in Language Studies, Oct., 118128.

Kiraly, D. C. (2000). A social constructivist approach to translator education: Empowerment from theory to practice. St Jerome.

Kohn, K., \& Kalina, S. (1996). The strategic dimension of interpreting. Translators' Journal, 41(1), 118-138.

Li, D. (2004). Trustworthiness of think-aloud protocols in the study of translation processes. International Journal of Applied Linguistics, 14(3), 301-313.

Livingston, S., Singer, B., \& Abramson, T. (1995). A study to determine the effectiveness of two different kinds of interpreting. In E. Winston (Ed.), Mapping our course, a collaborative venture. Proceedings of the $10^{\text {th }}$ National Convention of Interpreter Trainers (pp. 174 - 203). USA: CIT Publications

Marschark, M., Sapere, P., Convertino, C., \& Seewagen, R. (2005). Access to postsecondary education through sign language interpreting. Journal of Deaf Studies and Deaf Education, 10(1), 38-50.

Moser-Mercer, B. (1997). Process models in simultaneous interpretation. In C. Hauenschild \& S. Heizmann (Eds.) Machine Translation and Translation Theory (pp. 3-19). Berlin: Mouton de Gruyter.

Moser-Mercer, B., Frauenfelder, U. H., Casado, B., \& Kunzli, A. (2000). Searching to define expertise in interpreting. In B.E. Dimitrova \& K. Hylenstam (Eds.), Language Processing and Simultaneous Interpreting (pp. 107-132). [Place]: John Benjamins Translation Library

Napier, J. (2002). Linguistic coping strategies of interpreters: An exploration. Journal of Interpretation, 63-91.

Napier, J., \& Barker, R. (2004). Accessing university education: Perceptions, preferences, and expectations for interpreting by deaf students. Journal of Deaf Studies and Deaf Education, 9(2), 228-238.

Napier, J., \& Barker, R. (2004). Sign language interpreting: The relationship between metalinguistic awareness and the production of interpreting omissions. Sign Language Studies, 4(4), 369-393.

Pöchhacker, F. (2004). Introducing interpreting studies. London: Routledge.

Registry of Interpreters for the Deaf. (2005). Code of professional conduct. Retrieved from http://rid.org/ethics/code/index.cfm on 30/08/2013.

Roy, C. B. (1999). Interpreting as a discourse process. Oxford University Press.

Schön, D. A. (1983). The reflective practitioner: How professionals think in action (Vol. 5126). [USA]: Basic Books.

Seal, B. C. (2004). Psychological Testing of Sign Language Interpreters. Journal of Deaf Studies and Deaf Education, 9(1), 39-53.

Stone, C., \& West, D. (2012). Translation, representation and the Deaf 'voice'. Qualitative Research, 12(6), 645-665. 
Taylor, M. M. (1993). Interpretation Skills: English to American Sign Language. Edmonton, Alberta: Interpreting Consolidated.

Taylor, M. M. (2002). Interpretation Skills: American Sign Language to English. Edmonton, Alberta: Interpreting Consolidated.

TechSmith Inc. (n.d.). Camtasia:mac Computer software, Vers. 2.4 [computer software]. Retrieved from http://www.techsmith.com/camtasia.html on 30/08/2013.

Whittington, M. S., Lopez, J., Schley, E., \& Fisher, K. (2000). Using thinkaloud protocols to compare cognitive levels of students and professors in college classrooms. Proceedings of the $27^{\text {th }}$ annual national agricultural education research conference, 613-624.

Wilcox, S., \& Shaffer, B. (2005). Towards a cognitive model of interpreting. In T. Janzen (Ed.), Topics in Signed language Interpreting (pp. 27-50). [Philadelphia, PA]: Benjamins Translation Library.

Winston, E., \& Monikowski, C. (2003). Marking topic boundaries in signed interpretation and transliteration. In M. Metzger, S. Collins, V. Dively $\&$ R. Shaw (Eds.), From topic boundaries to omission: New research on interpretation (pp. 187-227). Washington, D.C.: Gallaudet University Press.

Witter-Merithew, A., \& Johnson, L. (2004). Market disorder within the field of sign language interpreting: Professionalization implications. Journal of Interpretation, 4, 19-56.

Witter-Merithew, A., Johnson, L., \& Taylor, M. (2004). A national perspective on entry-to-practice competencies. In E. Maroney (Ed.), Proceedings of the $15^{\text {th }}$ National Convention of the Conference of Interpreter Trainers, pp 23-42. CIT Publications. Retrieved from http://www.cit-asl.org. 